\title{
Determination of Tetracycline Residues in Honey from Tabora and Singida Regions Tanzania Produced Using Modern Beehives
}

\author{
Mohamed Hamed Sango Ally ${ }^{1, ~ *, ~ M n y a k a v i l l i ~ A n n a ~}{ }^{2}$ \\ ${ }^{1}$ Department of Physiology, Biochemistry, Pharmacology and Toxicology, Sokoine University of Agriculture, Morogoro, Tanzania \\ ${ }^{2}$ Department of Chemistry and Physics, Sokoine University of Agriculture, Morogoro, Tanzania
}

Email address:

ally2005mood@yahoo.com (M. H. S. Ally)

${ }^{*}$ Corresponding author

\section{To cite this article:}

Mohamed Hamed Sango Ally, Mnyakavilli Anna. Determination of Tetracycline Residues in Honey from Tabora and Singida Regions Tanzania Produced Using Modern Beehives. International Journal of Food Engineering and Technology. Vol. 4, No. 2, 2020 , pp. $32-35$. doi: $10.11648 /$ j.ijfet.20200402.14

Received: September 18, 2019; Accepted: October 4, 2019; Published: September 3, 2020

\begin{abstract}
A liquid chromatographic tandem mass spectrometric (HPLC MS/MS) method is proposed for identification and quantification of antibiotics residues and metabolites in honey and other matrices such as water, manure, soil, meat and sediments. This method was used to detect tetracycline derived residues in honey samples from Tabora and Singida regions, Tanzania. This honey was obtained from modern beehives. Three hundred honey samples were tested for the presence of tetracycline derivative residues. Of the examined samples $15 \%$ had these drug residues. Majority of samples contained residues to a proportion of $0.002-0.008 \mathrm{mg} / \mathrm{kg}$. The findings show that tetracycline antibiotic residues are present in honey from Tabora and Singida regions, although in small concentrations, however, this can possibly influence the naturally occurring protective properties of this medicinal food. Also can lead to drug resistance to consumers. Prospective studies that simultaneously track both resistance genes and antibiotic residues will go far in resolving some of the gagging questions that cloud our understanding of antibiotic resistance dissemination.
\end{abstract}

Keywords: Honey, Tetracycline Residues, Mass Spectrometry, Tabora, Singida, Tanzania

\section{Introduction}

The association of human being and honey bees has existed since time immemorial [8], and honey remains an important product for human wellbeing. It is widely known and consumed as a food and medicine in various places all over the world [1]. It has also non consumptive uses. Also honey is historically an essential ingredient of diet and has been promoted currently around the world as a naturally protective product against various infections [11], or burns and wounds [7]. The antimicrobial effects of honey, attributed to the presence of hydrogen peroxide and the level of antioxidant power [11], appear to be influenced by type of honey. The dark colored varieties of honey are thought to posses more inhibitory properties on selected pathogens than light colored ones. Other properties of honey, among which is its antinflamatory activity, contributes to rapid pain, edema and exudates reduction.

Moisturing of wounds prevents tissue maceration and adherence of dressing to the wound bed [7]. However, the purity of the honey would determine the strength of these properties, including antimicrobial action. Drug residues reduce these natural properties in honey and may consequently affect adversely its antimicrobial activity. Specifically, these residues may contribute to microbial resistance thereby altering the beneficial effects of the honey. The antimicrobial properties of honey appear to result from its naturally occurring inhibine $[11,16]$, that have intrinsic antibacterial actions, including activities against bacterial strains that are generally resistant to commonly used drugs [2, $3,12]$. This honey protective property is making it a preferred natural product for studying less intrusive alternative for protection of patients.

The rediscovered medicinal properties have also increased 
in quality of this food. Among the factors determining honey quality, purity is the most important. Various chemical contaminants or residues of chemicals including drugs used for bee diseases are currently being researched vigorously and detection methods are continuously improving [14]. Improved detection methods would naturally give rise to more classes of drugs and other chemical residues being detected $[6,15]$. With the contaminant increase in proportional of honey samples reported as positive $[5,13,14]$

However, bees like other living organisms, suffer the consequence of disease, and beekeepers often use either preventive or therapeutic antimicrobials to protect bees, health and levels of honey production. The tetracyclines, among other agents, have been used consistently for treating foulbrood caused by Paenibacillus larave. Thus honey could have drug residues in detectable amounts, possibly having considerable consequences to consumer. Various methods used in detecting residual antimicrobials in food, may not be suitable for honey, a product having naturally occurring bacteriostatic substances $[2,16]$, but technological improvements in available methods are giving promising results [14]. The modified [10] Oka et al., 1987 method was used for detecting minute amounts of tetracycline derivatives.

\section{Materials and Methods}

\subsection{Standard Solutions}

Tetracyclines, Oxytetracycline, Chlortetracycline and Doxycycline standards were purchased from Sigma Aldrich, Germany. Standard stock solutions at $100 \mathrm{mg} / \mathrm{l}$ were prepared by dissolving $10 \mathrm{mg}$ of standard powered in $10 \mathrm{ml}$ ethanol. Working standard solutions at $1 \mathrm{mg} / 1$ were prepared by dilutions from the standard stock solution in ethanol. Roxithromycin, used as internal standard was purchased from Sigma. Standard stock solutions at $1000 \mathrm{mg} / \mathrm{l}$ were prepared in ethanol. Working standard solutions at $10 \mathrm{mg} / \mathrm{l}$ were prepared by dilution from standard stock solutions in ethanol. Standard stock solutions were stored in dark bottles at $4{ }^{\circ} \mathrm{C}$ and were stable for two months. Working standard solutions were stored in same conditions for one month.

\subsection{Fortified Samples}

Tetracycline, Oxytetracycline, Chlortetracycline and Doxycycline concentrations in honey samples of 10, 15, 20, 25 and $30 \mu \mathrm{g} / \mathrm{kg}$ were obtained by spiking $50 \mathrm{~g}$ of negative control honey with 55, 120, 210, 350 and $600 \mu$ l of working solutions respectively. Spiked and blank honey samples were mixed with a small volume of $100 \mu \mathrm{l}$ of roxithromycin working standard solutions.

\subsection{Reagents and Equipment}

Ammonium acetate, Tris (Hydroxmethyl amonomethane) and $30 \%$ aqueous ammonia solution were purchased from
Sigma Aldrich, were of the highest purity grade. Solvents such as acetonitrile, ethanol, methanol were purchased from Sigma Aldrich were all high performance liquid chromatography grade. Distilled water was deionised by MilliQ apparatus from Millipore.

\subsection{Sample Preparation}

Three hundred samples of honey produced across Tabora and Singida regions using modern beehives were evaluated for tetracycline residues. Tetracycline (TC) Oxytetracycline (OTC), Chlortetracycline (CTC), and Doxycycline (DC) were detected according to Oka et al., 1987 by a Hewlett Packard 1100 liquid chromatographer (Hewlett Packard Inc with a Diode Array Detector and a Discovery C18 separation column $(25 \mathrm{~cm} \times 4.6 \mathrm{~mm}, 5 \mu \mathrm{m})$, at a light wavelength of $360 \mathrm{~nm}$. Specifically, purification of samples was achieved by diluting $15 \mathrm{~g}$ of honey in $30 \mathrm{ml}$ of EDTA $(0.1 \mathrm{~m}$ and $\mathrm{pH}$ of 4$)$. The solution was passed through glass wool (SUPELCO), filters before it was further purified through a Baker column 10C18 (SUPELCO) suitable for separating organic compounds. The column was washed with $10 \mathrm{ml}$ distilled water and further cleaned by passing of high speed $\mathrm{N}_{2}$ gas. Any remaining organic compounds were removed by passing through the column of $5 \mathrm{ml}$ of ethyl acetate having $10 \%$ of $\mathrm{MeOH}$. The collected solutions were passed again through a $10 \mathrm{COOH}$ Baker column, which was washed with $3 \mathrm{ml}$ of $\mathrm{MeOH}$. Final purification was achieved with the passing of $0.01 \mathrm{~m}$ and $\mathrm{pH} 3$ oxalic acid solutions, methanol and acetonitrile in a ratio of 5.4.1 respectively. The final solutions were tested by liquid chromatographer using positive control samples having $0.30,0.20,0.04$ and $0.001 \mathrm{mg} / \mathrm{kg}$ of OTC (Oxytetracycline), TC (Tetracycline), CTC (Chlorotetracycline) and DC (Doxytetracycline) respectively.

\section{Results}

Fifteen percent of the examined samples had drug residues. The range of detected amount of each observed drug residues in examined samples was 0. 002-0.005, $0.006-0.008, \quad 0$. 001-0031 and $0.004-0 \quad 0072 . \mathrm{mg} / \mathrm{kg}$, doxycycline, chlorotetracycline, oxytetracycline and tetracycline respectively. With reproducibility of $90 \%, 93 \%$, $91 \%$ and $97 \%$ for doxycyccline, chlortetracycline, oxytetracycline and tetracycline respectively. Positive samples detected and regions they have originated are detailed in Table 1. The highest proportion of positive samples originated from Tabora which was $23 \%$ and only $3.8 \%$ from Singida region. Most of the positive samples were positive for tetracycline 29 samples, oxytetracycline 14 samples. Honey samples from Singida region appear to have the lowest concentrations of drugs and that of Tabora the highest. 
Table 1. Number of positive samples to each antimicrobial agent, area of origin and range of drug residues.

\begin{tabular}{|c|c|c|c|c|c|c|c|}
\hline \multirow{2}{*}{ Area } & \multirow{2}{*}{ No } & \multirow{2}{*}{ positive samples } & \multirow{2}{*}{ Negative samples } & \multicolumn{4}{|c|}{ Antimicrobial (+) } \\
\hline & & & & TC & DC & OTC & CTC \\
\hline Sikonge & $\begin{array}{l}90 \\
0.005-0.0054 \\
0.002-0.007\end{array}$ & 23 & 67 & 10 & 13 & & \\
\hline Uyui & $\begin{array}{l}40 \\
0.001-0.0032 \\
0.003-0.005\end{array}$ & $\begin{array}{l}10 \\
1\end{array}$ & 30 & 9 & & & \\
\hline Urambo & $\begin{array}{l}41 \\
0.004-0.006\end{array}$ & 7 & 34 & 7 & & & \\
\hline Iramba & $\begin{array}{l}52 \\
0.0011-0.0032\end{array}$ & 1 & 51 & 1 & & & \\
\hline Manyoni & $\begin{array}{l}30 \\
0.002-0.008 \\
0.002-0.007\end{array}$ & $\begin{array}{l}4 \\
1\end{array}$ & 26 & 3 & & & \\
\hline $\begin{array}{l}\text { Mkalama } \\
\text { Total }\end{array}$ & $\begin{array}{l}47 \\
300\end{array}$ & $\begin{array}{l}0 \\
45\end{array}$ & $\begin{array}{l}47 \\
255\end{array}$ & 29 & 1 & 14 & 1 \\
\hline
\end{tabular}

Key. TC (Tetracycline), DC (Doxycycline), OTC (Oxyteracycline), CTC (Chlortetracycline).

\section{Discussion}

Beekeeping in Tanzania plays a major role in socio economic development and environmental conservation. It is a source of food (e.g. honey, pollen and brood), raw materials for various industries (e.g beeswax candles, lubricants), medicine (honey, propolis, beeswax bee venom) and source of income to beekeepers. Also beekeeping plays a major role in improving biodiversity and increasing crop production through pollination. In Tanzania honey is highly produced in Tabora region (Sikonge, Nzega, Igunga, Urambo, Uyui and Tabora districts), Singida region (Manyoni, Iramba and Mkalama districts), Shinyanga (Kahama and Bukombe districts), Rukwa (Mpanda district), Songwe (Chunya district) [9]. Scarce information is available in literature in Tanzania concerning the presence of antibiotic residues in honey. The findings are evidence of rising problem with possible health consequences to honey consumers. Thus one understand that, in the absence of international set acceptable amounts of antibiotic residues including tetracycline residues or standard methods for detecting them, population is involuntarily exposed to antibiotics residues unknowingly through honey consumption.

The present findings compare well with those others [14], using similar methodology. The method used here detects minute amounts of drugs residues, thus it has high reproducibility and sensitivity with tendency increase in proportion of true positive samples. A relatively high proportion of examined samples are thus positive to one or more of the tetracycline derivatives. The findings indicate a frequent use of tetracyclines derivatives. The reason for this frequent use could have arisen from easier access connected with pricing, flexibility of use or the need to go above the normal dose in response to dwindling efficacy. These scenarios inexorably give rise to residues accumulation in honey or a concomitant increase in microbial resistance when the honey is used against microorganisms [5, 4, and 13]. However, lack of information on findings and methods used for drug detection in honey point to the need for more work.
This work should show the spread and levels of honey contamination by drugs used in apiculture, with or without official permission and will help food agencies and government to further regulate the use of antibiotics and antiparasitic drugs in apiculture. Currently, world restrictions of common antibiotics in apiculture call for more research on the suitable drugs used in combating bee infections or parasitic diseases.

\section{Conclusion}

Beekeeping in Tanzania has a great potential of contributing to poverty reduction through income generation to beekeepers and government, creating employment to community and improving biodiversity. However, application of antibiotics for therapeutic and prophylaxis should be monitored to prevent antibiotic residues accumulation in honey, which may have public health concern to consumers.

\section{Conflict of Interest}

We declare that there is no conflict of interests.

\section{Acknowledgements}

We greatly acknowledge cooperation from all authorities in the study area.

\section{References}

[1] Batt PJ, Liu A 2012. Consumer behavior towards honey products in western Australia. Brit Food J. 114. 285-297.

[2] Ceyhan H, Ugur A, 2001. Investigation of in vitro antimicrobial activity of honey. Review in Biology 94, 363371.

[3] Dixion B, 2003. Bacteria can not resist honey. Lancent Infectious diseases 2, p116. 
[4] Evans J. D. 2003. Diverse origins of tetracycline resistance in honey bee bacterial pathogen Paenibacillus larvae. Journal of International Pathology, 83, 46-50.

[5] Heering W, Usleber E, Dietrich R and Martlbauer E, 1998. Immunochemical screening for antimicrobial drugs residues in commercial honey. Analyst 123, $275-2762$.

[6] Kaufmann A, Roth S, Ryser B, Widmer M and Gruggisberg D 2002. Quantitative LC MS MS determination of sulfonamides and some other antibiotics in honey. Journal of $A O A C$ International, 85, 853860 .

[7] Molan P. C, 2002. Re introducing honey in the management of wounds, ulcers, theory and practice. Ostomy/wound management, 48, 28-40.

[8] Muli E, Munguti A, Raina SK (2007. Quality of Honey Harvested and Processed Using Traditional Methods in Rural Areas of Kenya. Acta Vet Brno, 76. 315-320.

[9] Ngaga Y. M, Otsyana R, Senkondo E and Mpuya P 2005. Economic Survey on the role of beekeeping on poverty reduction and environmental conservation in Chunya, Songea and Nachingwea districts, Tanzania.

[10] Oka H, Ikai Y, Kawamura N, Unok K, Yamada M, Harrada K, and Suzuki M, 1987. Improvement of chemical analysis of antibiotics XII. Simultaneous analysis of seven tetracyclines in honey. Journal of Chromatography, 400, 253-261.
[11] Taormina P. J, Niemira B. A, Benchat L. R 2001. Inhibitory activity of honey against food borne pathogens as influenced by the presence of hydrogen peroxide and level of antioxdant power. International Journal of Food Microbiology, 69, 217225 .

[12] Tichy J and Novak J, 2000. Detection of antimicrobials in bee products with activity against viridans streptococci. Journal of Alternative and Complementary Medicine, 6, 383-389.

[13] Verzegnessi L, Royer D, Mottier P and Stadler RH 2003. Analysis of chlorompenicol in honeys of different geographical origins by liquid chromatography coupled to electrospray ionisation tandem mass spectrometry. Food additives and Contaminants, 20, 335-342.

[14] Vinas P, Balsalobre N, Lopez Erroz C, Hernandez Cordoba M, 2004. Liquid chromatography with ultraviolet absorbance detection for the analysis of tetracycline residues in honey. Journal of chromatographic Analysis, 1022, 125-129.

[15] Wang J. 2004. Confirmatory determination of six penicllins in honey by liquid chromatography/eletrospray ionisation tandem mass spectrometry. Journal AOAC International, 187, $45-55$.

[16] Zaghloul A. A, El shattawy H. H, Kassem AA, Ibrahim EA, Reddy IK and Khan MA 2001. Honey, a perspective antibiotic, Extraction, formulation and stability. Die Pharmazie, 56, 643647. 